\title{
THE PREPARATION OF ACCURATE STANDARD MIXTURES OF INHALATION ANAESTHETIC AGENTS*
}

\author{
R. HerChL, Ph.D.†
}

\begin{abstract}
ANAESTHETIC RESEARCH requires the evaluation of anaesthetics and other gas concentrations in blood and gas. The first step in such analysis is the preparation of precise and reproducible standards. Gas-gas standards are prepared using flowmeters and mixing together known volumes of gases. For vapour-gas mixtures, a continuous stream of liquid anaesthetic is allowed to drip into a gas stream of known flow-rate. ${ }^{1}$ From the liquid and gas flow-rates, the concentration in the mixture may be calculated. However, it is difficult to hold flows steady. ${ }^{2}$ Vapourgas mixtures are also prepared by weighing a quantity of a liquid anaesthetic and evaporating it in a known gas volume in a container. ${ }^{3}$ This method is very simple but is subject to errors which occur mainly when taking second and subsequent samples from the container.

Our objective was to develop a laboratory device and method to prepare both gas-gas and vapour-gas standards with precision and reproducibility which would avoid many of the above difficulties.
\end{abstract}

\section{Method}

An adjustable measuring syringe (Figure 1) is used to measure gas volumes under constant pressure. Volumes of two gases are then mixed in various proportions to obtain known percentage mixtures.

To prepare anaesthetics vapour-gas mixture, a saturated vapour is generated and mixed to obtain the desired percentage.

\section{ApPaRatus}

Two systems were used. Figure 2 is an apparatus for preparing gas-gas mixture, and Figure 3 for preparing saturated vapour of anaesthetics and measuring its volume.

The system shown in Figure 2 consists of a manifold made up of standard three-way stopcocks (B-D stopcocks, B-D stopcock manifold and B-D adapters). At one end of the manifold a nylon bag is attached which contains an anaesthetic gas or any other gas at ambient pressure. At the other end of the manifold is a sensitive pressure gauge. Three glass syringes are connected to the manifold: a $50 \mathrm{ml}$ volume adjustment syringe, a $50 \mathrm{ml}$ pressure equilibrating syringe, and a

\footnotetext{
-This work has been been supported by a grant from The Canadian Foundation for the Advancement of Therapeutics. toba.

†Associate Professor, Department of Anaesthesia, University of Manitoba, Winnipeg, Mani-
} 


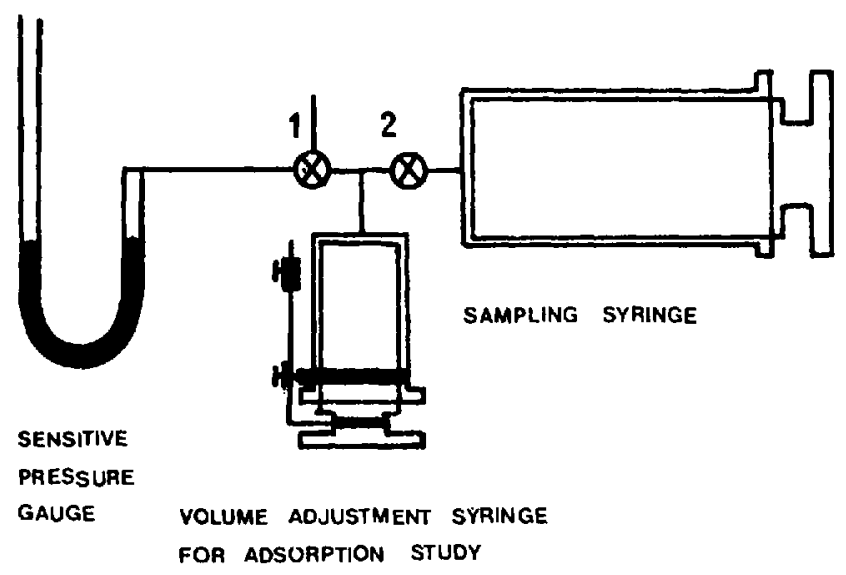

Figune 1. Volume Adjustment Syringe.

$200 \mathrm{ml}$ sampling syringe. The volume adjustment syringe (Figure 1) has a special attachment enabling it to contain on repeated occasions an equal volume of a gas (or vapour). The pressure gauge and sampling syringe, as well as the nylon bag are connected to the manifold by teflon tubing.

Figure 3 is similar to Figure 2, except that vaporizers of a liquid anaesthetic in a 35-litre water bath are inserted betwen the bag and manifold. The water bath is about $1-1.5^{\circ} \mathrm{C}$ below the room temperature. Because of this, vapour does not condense in the tubing. ${ }^{4}$ A stirrer keeps the water moving in the bath, maintaining equal temperature in the vessel. Two vaporizers filled with a

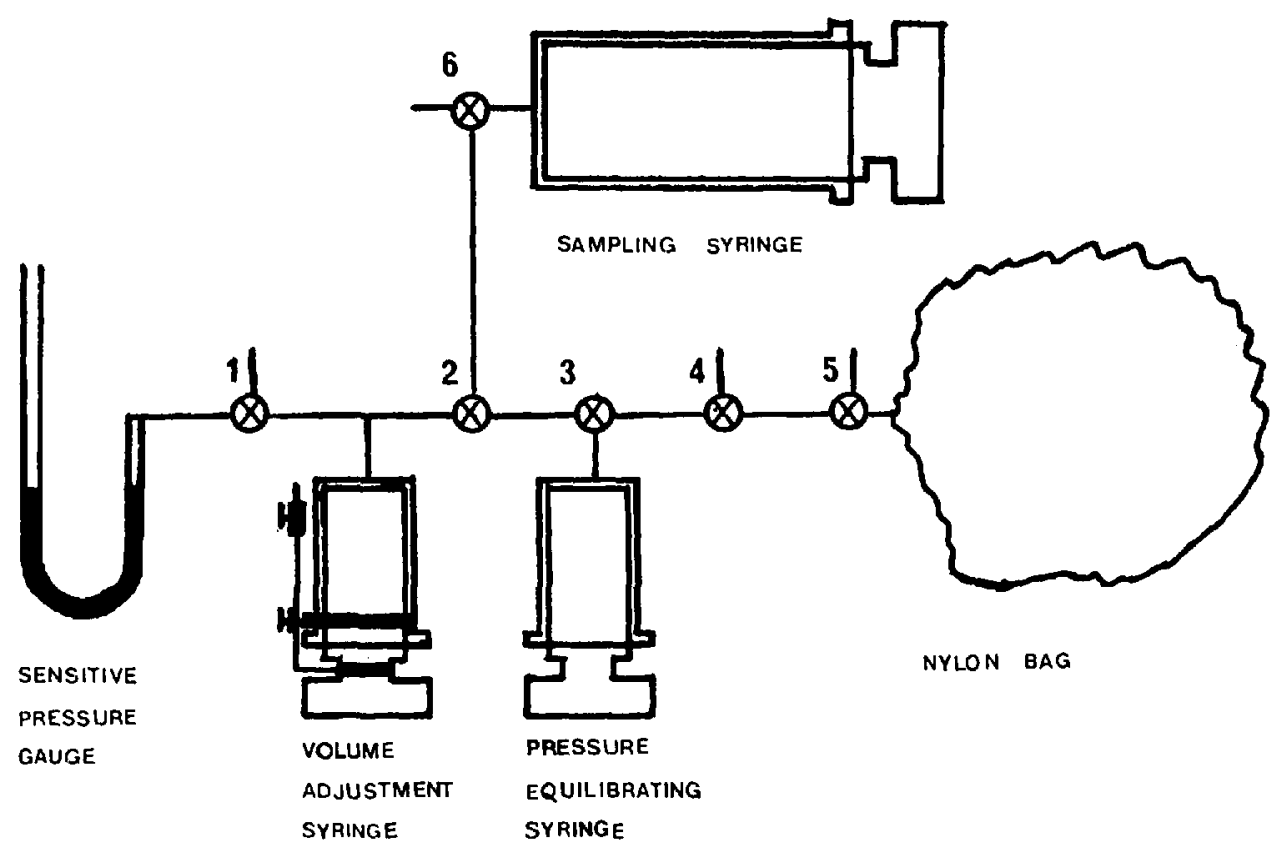

Figure 2. Apparatus for preparing gas-gas mixtures. 


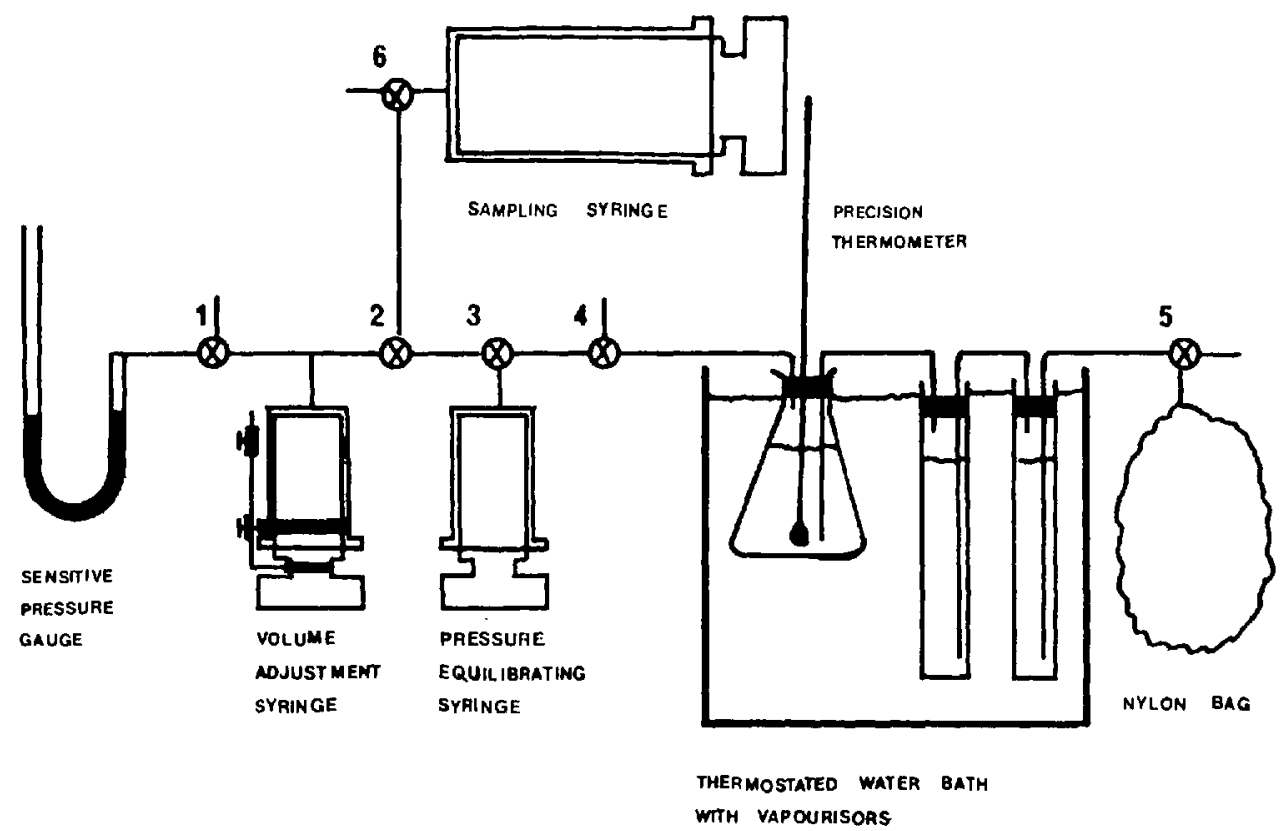

FIGURE 3. Assembly for preparing saturated vapours of anaesthetic agents and their volume measuring.

liquid anaesthetic ( $30 \mathrm{~cm}$ deep) are made of copper (inside diameter $18 \mathrm{~mm}$ ), which permits quick transfer of consumed latent heat of evaporation from the surrounding water. The third vaporizer is an Erlenmeyer glass flask (12 cm deep) and contains a precision thermometer. If the gas passing through the first vaporizer does not become saturated with anaesthetic vapour, then saturation almost certainly occurs in the second one. If the bubbling gas is still not saturated completely in the copper vaporizers, it will evaporate a little of the liquid in the glass flask. If evaporation occurs, the liquid in the flask will cool down a little because of lag in heat transfer through glass. Cooling will be indicated on the thermometer scale which has divisions of $0.05^{\circ} \mathrm{F}\left(0.032^{\circ} \mathrm{C}\right)$. If the thermometer shows a stable temperature while a gas bubbles through the flask, this gas must be saturated with anaesthetic vapour at the temperature shown on the thermometer scale. Connections in the system are made of metal and teflon, which do not adsorb gases or vapours. A portable Airflow Testing Set, Mark I (Airflow Development Ltd., England) is used for measuring pressure. Experimental results are controlled by an interferometer (VEB Zeiss, Jena).

\section{Procedures for Standard Mixtures Preparation}

\section{Gas-Gas}

When preparing a mixture, for example a 20 per cent mixture of gas a in air, the system shown in Figure 2 would be used. Firstly, the volume of the volume adjustment syringe must allow for 5 fillings (in this particular case) to be trans- 
ferred into the sampling syringe $(200 \mathrm{ml})$; that is, the adjusted volume must be a maximum of $40 \mathrm{ml}$. Using the syringes, the whole system is flushed with gas $A$ sucked from a nylon bag. The next step is to suck gas $\mathrm{A}$ into the pressure equilibrating syringe through valves 3,4 and 5 . The volume adjustment syringe is then filled with gas a from the bag, the plunger being withdrawn to the chosen volume adjustment. The gas flows through valves $2,3,4$ and 5 . By connecting the pressure equilibrating syringe and the sensitive pressure gauge, using valves 1,2 and 3 , the pressure in the system is set at ambient pressure by adjusting the plunger in the pressure equilibrating syringe. Turning off valve 3 by turning valve 2 into the proper position, permits us to transfer the gas from the volume adjustment syringe into the sampling syringe. By joining the volume adjustment and sampling syringes with the pressure gauge through valves 1,2 and 6 , it is possible to control pressure within the system while transferring the gas. When transfer is completed, the pressure in the system is once more checked and if necessary, adjusted by the plunger of the sampling syringe. The sampling syringe is then closed by valve 6 . Now, the nylon bag with gas $\mathrm{A}$ is replaced by another nylon bag filled with pure air (from a tank). The system is flushed out with air twice, and the procedure with air follows the same pattern as for gas A. The volume adjustment syringe is filled with air, till the same adjustment is reached as previously, and emptied four times into the sampling syringe. There is now a total of $200 \mathrm{ml}$ of gases in the sampling syringe. After pressure equilibration, valve 6 isolates the mixture in the sampling syringe and the syringe is disconnected from the system. To mix the gases properly, the syringe is connected with a $200 \mathrm{ml}$ empty syringe. By pushing the gas mixture from one syringe into the other, and back, the gases are mixed perfectly and ready for use as a standard.

\section{Vapour-Gas}

When preparing a mixture of anaesthetic vapours and gases it is necessary to add vaporizers into the system as shown in Figure 3 . To obtain saturated vapour of penthrane in air, air must be withdrawn from the nylon bag through the vaporizers filled with penthrane by means of the syringes, and the system flushed out as in previous method (Figure 2). When the samples sucked into the measuring syringe show reproducibility on five or more successive interferometer analyses, the gaseous mixture of penthrane in air is saturated at the temperature given by the precision thermometer. Now, the saturated vapour can be diluted with air into desirable concentrations. The volume of the volume adjustment syringe is adjusted. Saturated vapour is sucked into the pressure equilibrating and volume adjustment syringes and the estimation is conducted in a similar fashion to that used for preparation of gas-gas mixtures. Then, from the volume adjustment syringe, vapour is transferred into the sampling syringe and valve 6 closes it. The sampling syringe as well as the volume adjustment syringe are then disconnected from the system shown in Figure 3 and attached to the system in Figure 2. The volume adjustment syringe and the manifold are carefully flushed out with air. Now, the saturated vapour in the sampling syringe can be diluted in the desired volume ratio with air. To conclude, the contents of the sampling syringe are mixed in the way previously described. 


\section{RESULTS}

To study the reproducibility of a gas-gas mixture, nitrous oxide was mixed with oxygen. At each concentration, 10 samples were prepared as previously described, and analysed by an interferometer. Reproducibility was better than \pm 0.1 per cent.

To study the reproducibility of vapour-gas mixtures, penthrane and halothane respectively were mixed with air according to the described procedure. At each concentration, 5 samples were prepared and analysed by an interferometer. Reproducibility was better than \pm 0.2 per cent.

TABLE I

Statistically Expressed Data For Various Mixtures of Gaseous AnaEsthetics

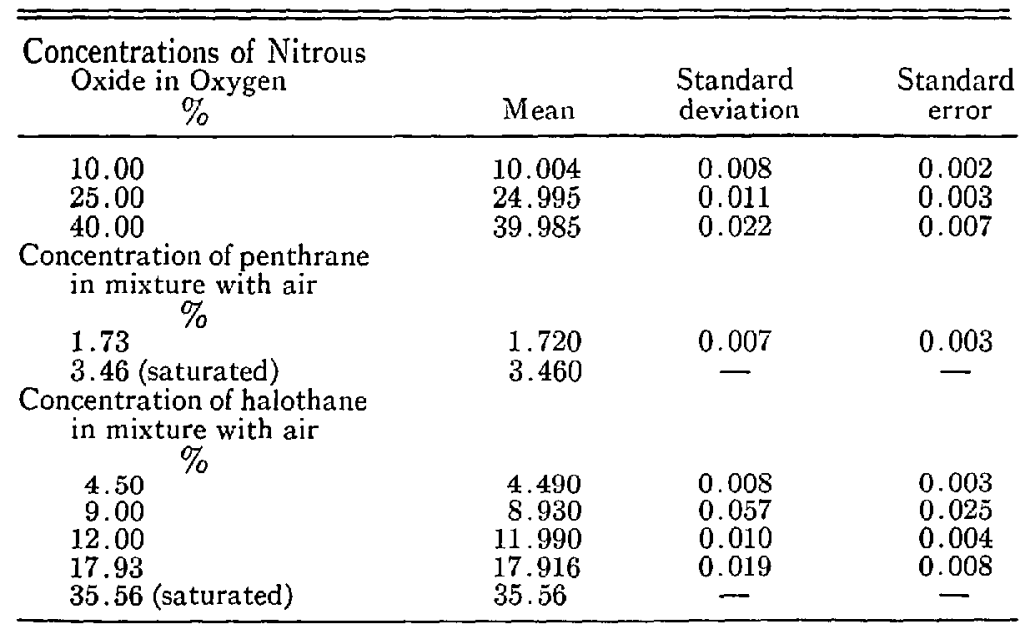

\section{Discussron}

To determine saturated vapour pressure at given temperature for a liquid anaesthetic, the equation for that particular liquid is used.5,6 The value of calculated concentration is then adjusted according to the barometric pressure. If calculated saturated vapour pressure is " $\mathrm{p}$ " and the barometric pressure "P", the volume-to-volume percentage will be:

$$
\text { vol. per cent }=\mathrm{p} / \mathrm{P} \times 100
$$

After calculating the volume-to-volume concentration, the ratio of air required to dilute it to lower concentration can be easily estimated.

The systems illustrated in Figure 2 and Figure 3 were mounted on one manifold originally, simply by attaching the nylon bag in Figure 2 to the outlet of valve 4 in Figure 3. However, it was difficult to flush out anaesthetic droplets from the manifold. Therefore, the systems were built separately.

An interesting finding in these experiments was the adsorption of anaesthetic vapours on the ground glass wall of the syringes. ${ }^{7}$ This problem was overcome by saturating the syringe walls by exposing them to the same gaseous mixture for 
about one hour prior to preparation of the standard mixture. After this arrangement, no significant deviation in reproducibility was found. There also was no evidence that the teflon tubing or the metal manifold adsorbed the anaesthetics. The rubber stoppers in the vaporizers were wrapped in nylon to prevent adsorption-desorption respectively.

A bath temperature lower than room temperature, and controlled pressure while transferring measured saturated vapour into the sampling syringes ensured that saturated vapour did not condense in the manifold. It is rather more difficult to obtain mixtures with a low vapour concentration percentage for an anaesthetic with a high saturated vapour pressure, such as halothane. For example, to obtain 0.9 per cent halothane vapour in air, one part of saturated halothane vapour which contains 36.00 vol. per cent of halothane if saturated at $22.8^{\circ} \mathrm{C}$ must be mixed with 39 parts of air. That means 39 times of measuring the same volume of air, which is awkward, of course. On the other hand, to calibrate an interferometer, the lowest concentration of halothane sufficient for the purpose would be about 4 per cent. In this case the ratio of saturated vapour to air is 1:7.

\section{SUMMARY}

A method and apparatus for preparation of accurate gaseous anaesthetic mixtures was developed. It is applicable to anaesthetic gas-gas as well as anaesthetic vapour-gas mixtures. Prepared mixtures can be used as standards for calibration of an interferometer or gas-chromatograph or any other equipment needing such standards. Reproducibility is better than \pm 0.1 per cent for gas-gas mixtures and better than \pm 0.2 per cent for vapour-gas mixtures.

\section{RÉSUMÉ}

Nous avons mis à point une méthode et un appareil pour la préparation de mélanges exacts, précis d'anesthésiques gazeux. Ils peuvent être employés aussi bien pour des mélanges gaz anesthésiques-gaz que pour des mélanges vapeurs anesthésiques-gaz. Des mélanges préparés peuvent servir d'étalons pour calibrer un interféromètre ou un chromatographe à gaz ou tout autre appareil requérant de tels prototypes ou étalons. La reproducibilité est supérieure à \pm 0.1 pour cent pour les mélanges gaz-gaz et supérieure à \pm 0.2 pour cent pour les mélanges vapeur-gaz.

\section{REFERENCES}

1. JAHN, R. E. The Analyst. 80: 700 (1955).

2. HILL, D. W. Brit. J. Appl. Phys. 12: 410 (1961).

3. Eger, E. T. II. Personal Communication

4. Mustin, W. W. \& Erstern, H. G. Physics for the Anaesthetist. (1958) p. 45.

5. Herchl, R. An Equation for the Calculation of the Saturated Vapour Pressure of Penthrane (to be published).

6. HrLL, D. W. Brit. J. Anaesth. 38: 476 (1966).

7. Herchl, R. Adsorption Studies of Halothane Vapour in Glass-Syringes (to be published). 